\title{
A Judicialização da Política e a Atuação Política dos Juristas em Perspectiva Comparada: Os Casos Brasileiro e Estadunidense ${ }^{1}$
}

\author{
The Judicialization of Politics and the Political Performance of \\ Jurists in a Comparative Perspective: The Brazilian and \\ American Cases
}

Michel Lobo Toledo Lima

\begin{abstract}
RESUMO
O presente trabalho analisa e compara os diferentes processos políticos que envolvem os recentes usos e atuações do Judiciário no contexto brasileiro e estadunidense. Para tanto serão utilizados os conceitos de judicialização da política de Luiz Werneck Vianna e outros que dispõe do Poder Judiciário como ator político no Brasil, e os processos judiciais enquanto engajamento político de demandas judiciais e como catalizadores de processos políticos em Michael W. McCann. A comparação aqui se refere a apresentar por contraste os processos de atuação política dos juristas no Brasil e nos EUA a partir de trabalhos dos autores citados com o fim de debater as distintas abordagens da atuação política dos juristas na sociologia do direito brasileiro e estadunidense, enfatizando as tradições de pesquisa que se desdobraram nestes países e focando fenômenos próprios a estes contextos.
\end{abstract}

\section{PALAVRAS-CHAVE:}

Judicialização. Processos judiciais. Sociologia do direito. Demandas judiciais. Judiciário.

\begin{abstract}
The present work analyzes and compares the different political processes that involve the recent uses and actions of the Judiciary in the Brazilian and American context. To this end, Luiz Werneck Vianna's concepts of judicialization of politics and others that have the Judiciary as a political actor in Brazil will be used, and judicial processes as political engagement of judicial demands and as catalysts of political processes in Michael W. McCann. The comparison here refers to presenting, by contrast, the processes of political action by jurists in Brazil and the USA based on the works of the aforementioned authors in order to debate the different approaches to political action by jurists in the sociology of Brazilian and American law, emphasizing the research traditions that unfolded in these countries and focusing on phenomena specific to these contexts.
\end{abstract}

\footnotetext{
${ }^{1}$ Uma versão preliminar desse trabalho foi submetida para a coletânea Direito e Conflitos em Perspectiva Empírica do Grupo Interdisciplinar de Pesquisa sobre Administração de Conflitos da Universidade Católica de Petrópolis.

${ }^{2}$ Graduado em Direito pela Pontifícia Universidade Católica do Rio de Janeiro - PUC-Rio. Doutor e mestre em Sociologia pelo Instituto de Estudos Sociais e Políticos da Universidade do Estado do Rio de Janeiro - IESP/UERJ. Pós-graduado em Políticas Públicas de Justiça Criminal e Segurança Pública pela Universidade Federal Fluminense - UFF. Pesquisador do Instituto de Estudos Comparados Em Administração Institucional de Conflitos (INCT/InEAC). Pós-doutorando FAPERJ nota 10 na Universidade Veiga de Almeida. Áreas de Interesse: Sociologia com ênfase em Sociologia do Direito, Antropologia com ênfase em Antropologia do Direito, Direito Público e Segurança Pública.
} 


\section{KEYWORDS:}

Judicialization. Court lawsuits. Sociology of law. Judicial demands. Judiciary.

\section{INTRODUÇÃO}

Esse trabalho analisa e compara os diferentes processos políticos que envolvem os recentes usos e atuações do Judiciário no contexto brasileiro e estadunidense. Para tanto serão utilizados os conceitos de judicialização da política de Luiz Werneck Vianna, Manuel Palacios Cunha Melo, Maria Alice Rezende e Carvalho e Marcelo Baumann Burgos, que dispõe do Poder Judiciário como ator político no Brasil, e os processos judiciais enquanto engajamento político de demandas judiciais e como catalizadores de processos políticos em Michael W. McCann. A comparação aqui se refere a apresentar por contraste os processos de atuação política dos juristas no Brasil e nos EUA a partir de trabalhos dos autores citados com o fim de debater as distintas abordagens da atuação política dos juristas na sociologia do direito brasileiro e estadunidense, enfatizando as tradições de pesquisa que se desdobraram nestes países e focando fenômenos próprios a estes contextos ${ }^{3}$.

No caso brasileiro, os estudos sobre a judicialização das relações sociais abordam o papel político dos juízes e do Ministério Público, propiciando uma análise a respeito dos poderes constituídos da república, enquanto que o caso estadunidense foca-se nos usos do direito pelos profissionais e associam a ação coletiva dos movimentos sociais com a construção e militância de causas jurídicas. Visa-se assim debater distintos aspectos sobre um mesmo fenômeno, a atuação política dos juristas, comparando as abordagens destes estudos empíricos a respeito do direito como uma prática social e enfatizando a reflexão sobre as relações entre as abordagens e os diferentes objetos de pesquisas privilegiados em cada um destes contextos de pesquisa.

\footnotetext{
${ }^{3}$ Boa parte dessas reflexões foi propiciada pela disciplina "A atuação política dos juristas numa perspectiva comparada (Brasil, França e EUA)" ministrada pelos professores Fernando de Castro Fontainha e Pedro Heitor Barros Geraldo no Programa de Pós-Graduação do IESP/UERJ. Os debates foram compactados para o espaço aqui proposto.
} 


\section{O PARADOXO DA JUDICIALIZAÇÃO DA POLÍTICA: O CASO BRASILEIRO}

Os estudos sobre a judicialização das relações sociais e da política conduzido por Luiz Werneck Vianna e outros em $1997^{4}$ foram um dos que consolidaram a temática da judicialização da política no campo do direito brasileiro, trazendo imbricações entre a sociologia e o direito, demonstrando a riqueza de pesquisas que podem ser desenvolvidas nesse campo.

Os referidos autores ao analisarem o processo de judicialização da política e das relações sociais no Brasil partem das reflexões de Mauro Cappelletti e Bryant Garth e reapresentam três grandes movimentos que atingiram os países da commom law e da civil law desde os anos de 1960 (CAPPELLETTI. GARTH: 1988), no que tange o inchaço de processos no Judiciário, ao acesso à justiça, ao movimento processual e à efetividade de demanda direitos dos cidadãos nos países ocidentais. O primeiro movimento visou a promoção de assistência judiciária à litigantes de baixa renda e teve início nos Estados Unidos. O segundo movimento se deu com a emergência dos direitos difusos, que são direitos referentes ao interesse da sociedade, ligados a áreas que têm reflexo sobre toda a população, envolvendo assuntos relevantes de políticas públicas, a exemplo da ordem econômica, do meio ambiente e dos direitos do consumidor.

Por fim, o terceiro e mais recente movimento, conhecido como terceira onda surgiu enfatizando as formas não ortodoxas de resolução de conflitos no e do Judiciário, a exemplo da justiça privada. Países como Estados Unidos, Canadá, Alemanha, França, Inglaterra e Itália passaram por cada um dos três movimentos citados, impulsionados pela falência do modelo de Estado Assistencial do Welfare State. A terceira onda possui base na conciliação e negociação judicial, buscando a participação de membros da comunidade diretamente interessada no conflito em demanda judicial de resolução.

\footnotetext{
${ }^{4}$ WERNECK VIANNA, Luiz; REZENDE DE CARVALHO, Maria Alice; MELO, Manuel Palácios Cunha; BURGOS, Marcelo Baumann. A Judicialização da Política e das Relações Sociais no Brasil. Rio de Janeiro: Revan, 1999.
} 
A terceira onda teria sido o marco inicial de um constitucionalismo democrático nesses países (VIANNA. BURGOS. SALLES: 2007, p. 40), ou seja, do desenvolvimento de um Judiciário dotado da competência para desempenhar jurisdição sobre a legislação produzida pelo Estado enquanto poder soberano, a exemplo do caso estadunidense. A terceira onda foi assim uma resposta para controlar o poder estatal, principalmente o Executivo.

Portanto, essa necessidade de controle do Estado por uma via "alternativa" se deu, conforme o autor, pela primazia do Executivo sobre o Legislativo para a constituição de um Estado do Bem Estar Social que escolheria quais políticas públicas constataria em sua agenda política e como ela seria aplicada, publicizada e normatizada. O Poder Judiciário foi assim mobilizado para um papel de interpretador das normas, enquanto arena de luta por demandas de direitos não contemplados na agenda política estatal. Foi de uma agenda assistencialista, reguladora de mercado e igualitária de direitos do Welfare State que houve a redefinição atual da relação entre os três poderes, atribuindo ao Judiciário a função de controle de poderes políticos e de luta por reconhecimento de direitos, como no contexto estadunidense.

Da mesma forma que o Judiciário estadunidense se desenvolveu enquanto arena de demandas de causas judiciais de ativismo Judiciário por oposição a um Estado forte (MCCANN: 1994, p. 309-310), no Brasil o Judiciário teria se reformulado também por oposição a um Estado forte, porém num contexto e com transformações institucionais diferentes. O caso brasileiro possui uma tradição histórica da primazia da União sobre a federação, tendo dois marcos históricos de autoritarismo político: o primeiro de 1889 a 1930 com a República Velha, e o segundo, no período do regime militar de 1964 a 1985. Tendo por experiência dois momentos históricos de aguda centralização política e administrativa e de fragilidade constitucional, o nosso processo de democratização, concretizado simbolicamente e normativamente pela Constituição da República Federativa do Brasil de 1988, teve como imperativo para a realização de reformas políticas a remoção de barreiras à ampliação da economia e à democratização social. Portanto, diferente do contexto estadunidense, no Brasil, o Judiciário enquanto arena de luta por demanda de direitos não se deu pela via dos movimentos sociais, mas pela via institucional, por meio da Constituição Federal de 1988.

A Constituição de 1988 buscou inibir os elementos autoritários contidos nas constituições daqueles dois marcos históricos, sendo considerada uma constituição democrática 
e cidadã por estabelecer inovações institucionais na democracia brasileira. Consolidou princípios e instituições do liberalismo político, explicitou os direitos civis de cidadania e estipulou um desenho institucional voltado à democracia política. Porém, paradoxalmente, também se cultivou a representação funcional por meio do Ministério Público na defesa da ordem jurídica, do regime democrático e dos interesses e direitos sociais e individuais indisponíveis. Paradoxo, pois coexiste uma evocação constitucional de exercício de cidadania e de invocação do Judiciário enquanto arena de demanda de direitos simultaneamente com a estipulação de um representante institucional - o Ministério Público - para a defesa de interesses e direitos sociais e individuais. Essa representatividade funcional cultivou a figura de um "Estado Juiz" (WERNECK VIANNA. REZENDE DE CARVALHO. MELO. BURGOS:1999, p. 42), interventor nas relações sociais e políticas. Temos um Estado que é dono do processo judicial e que provém da tradição da civil law, que funda sua legitimidade em uma racionalidade abstrata, considerando os julgamentos técnicos dos juízes melhores que os de pessoas comuns, por deterem um saber jurídico especializado (LIMA: 2010, p. 30).

Cátia Aida em sua pesquisa ${ }^{5}$ sobre as formas de atuação do Ministério Público em comarcas do interior e da capital de São Paulo também apontou para os dilemas e paradoxos de uma Constituição invocadora de exercícios de cidadania com obrigatoriedade de representatividade institucional no campo jurídico, categorizando dois tipos de promotores de justiça. De um lado, havia os promotores de fato que desenvolviam novas atribuições constitucionais do Ministério Público enquanto fonte de poder a ser empregado na transformação da sociedade. Enquanto que de outro lado, havia os promotores de gabinete que demonstravam incômodo com os limites impostos pela realidade apreendida e às linhas tênues entre o campo jurídico e o universo de ações de caráter social e político que exigia mais do que um operador do Judiciário deveria e poderia fazer.

Para além do Ministério público, o trabalho de Werneck Vianna e outros focou sua pesquisa para as ações diretas de inconstitucionalidade (Adin) enquanto instrumento de atuação política do Supremo Tribunal Federal e verificando os padrões de judicialização da política ao final do governo Itamar Franco, nos dois governos de Fernando Henrique Cardoso e nos três

\footnotetext{
${ }^{5}$ SILVA, C. A. Promotores de justiça e novas formas de atuação em defesa de interesses sociais e coletivos. Revista Brasileira de Ciências Sociais, v. 16, n.45, p. 127-144, fev 2001 b.
} 
primeiros anos do governo de Luiz Inácio Lula da Silva. A Adin se mostrou relevante por possibilitar a entrada de novos atores políticos na arena jurídica.

No texto original, de 1999, Werneck Vianna $e$ outros pesquisou no recorte temporal de 1998 a 1999 a mudança de perfil do Judiciário, dispondo a passagem de um grupo de juízes predominantemente comprometido com a tradição republicana brasileira à um grupo que introduziu o "mercado" como instância determinante da vida social, estimulado pelo novo texto constitucional de 1988. Percebeu-se novas tensões entre os três poderes e entre as políticas sociais introduzidas pela Constituição Federal de 1988 e a agenda liberal. Foi desse contexto que o Judiciário no Brasil foi percebido como uma possível via para as insatisfações existentes com o ativismo legislativo do Executivo, marcando a inauguração do processo institucional da judicialização da política. $\mathrm{O}$ autor demonstrou certo otimismo com a possibilidade de passagem de um positivismo jurídico kelseniano para um Judiciário como via de sociabilidade para a cidadania ativa, enquanto reivindicadora de direitos. Sua expectativa era que se formasse um Judiciário como nova arena para as controvérsias entre princípios e valores, ou seja, como um espaço para uma democracia mais participativa, com brechas para lutas por reconhecimento de demandas de direitos, a exemplo do contexto estadunidense pós-falência do Welfare State. A judicialização da política era vista como uma forma de controle do Judiciário sobre a vontade do soberano, o Estado.

Como resultados de sua pesquisa mais recente, de 2007, analisando dezessete anos de judicialização da política no Brasil, o autor constatou que o instrumento da Adin é muito influenciado pelas transformações políticas dos partidos nos governos no que tange aos atores que a utilizam, quase sempre empregado como uma ferramenta de disputa política e de exercício da oposição partidária. Outro resultado, mais intrigante, foi constatar que as ações diretas de inconstitucionalidade contra o legislativo e judiciário dos Estados se concentraram em matérias referentes à administração pública, ou seja, as Adins apresentavam-se como ferramenta de centralização e homogeneização da produção de normas dos Estados, pela União.

As decisões do Supremo Tribunal Federal atuam com o fim da manutenção da homogeneidade na produção normativa estadual. Portanto há outro efeito paradoxal apontado pelo autor, onde as Adins seriam originariamente uma forma de controle do Estado, para que este não se tornasse muito forte e interventor nas mais variadas esferas políticas e sociais da 
sociedade, porém elas acabaram por gerar um efeito contrário, reforçando e centralizando o poder estatal, o poder da União. E o papel do Ministério Público nesses casos possui relevância, onde sua atuação foi a que mais influenciou o aumento do número das Adins durante o governo Lula. Da mesma maneira também foi percebida a centralização das questões sociais pela União via políticas públicas, a exemplo da invenção das agências públicas de âmbito nacional, tal como Sistema Unificado de Saúde. Portanto, para além, e até num sentido oposto, de ser uma ferramenta de defesa de minorias, a Ação Direta de Constitucionalidade é, na prática, principalmente um recurso institucional estratégico de governos e partidos políticos, constituindo o Supremo Tribunal Federal como uma espécie de "Conselho de Estado" (Op. Cit. 2007: P. 44), reforçando a arquitetura estatal enquanto unitária e centralizadora.

\section{ATIVISMO JUDICIAL E MOVIMENTOS SOCIAIS: O CASO ESTADUNIDENSE}

Michael McCann analisa a atuação do Judiciário na regulação social e política da sociedade norte-americana, correlacionando as recentes relações das formas organizadas de mobilização no seio da sociedade civil por meio dos movimentos sociais com a Justiça ${ }^{6}$. Nesse aspecto, a mobilização do direito visa a robustecer o poder dos cidadãos marginalizados. $\mathrm{O}$ Judiciário aqui municia recursos estratégicos para a mobilização das lutas sociais. Em sua pesquisa $^{7}$, foram analisadas ações coletivas iniciadas pelos juristas dos sindicatos a respeito do pay equity ${ }^{8}$ de minorias, nos Estados Unidos, como as mulheres. Conforme o autor, para se estudar a atuação política dos juristas é necessário estudar a correlação entre intervenção de juristas em processos políticos e a reformulação desses processos (se houve mudança social ou não após suas intervenções).

O contexto estudado foi o da organização das feministas pelo fim da discriminação salarial. O autor demonstra como os movimentos iniciais vão se travestindo de lutas judiciais, permitindo a constituição de um discurso coeso a favor da equiparação remuneratória das

\footnotetext{
${ }^{6}$ A palavra "Justiça" é aqui utilizada no sentido de Judiciário. Daí sua escrita em letra maiúscula.

${ }^{7}$ MCCANN, Michael. W. Rights at Work: Pay Equity Reform and the Politics of Legal Mobilization. Chicago: University of Chicago Press, 1994.

${ }^{8}$ Em tradução livre: salário igual para trabalho igual.
} 
minorias discriminadas ${ }^{9}$. O desenvolvimento de ações políticas em lutas sociais veio da interação entre os advogados defensores do interesse público e as organizações. McCann destaca a necessidade em se avaliar o campo jurídico em interação com a vida social e política a fim de se perceber os usos do Direito na agenda em prol de direitos.

O autor dispõe que o contexto estadunisende pós Welfare State estimulou uma descrença social sobre as possibilidades de se ter o Judiciário como arena de disputa em favor de reformas sociais igualitárias. McCann aponta que os estudos, até a época de sua obra, que demonstravam a pouca utilidade das táticas jurídicas para reformas sociais não dispõem sobre os vários papéis possíveis das ações jurídicas nos embates políticos, já que leis e instituições jurídicas não garantem "justiça" 10 por si só, da mesma maneira que também não são entraves à busca de uma sociedade mais justa a priori. Deste modo, os anseios sociais, mesmo que não organizados em grupos, ao encontrarem um espaço institucionalizado às suas demandas, podem produzir uma transformação social e criar uma via de participação na agenda política estatal.

Assim, através de um estudo de caso sobre a mobilização legal do movimento de equidade de remuneração nos anos 70 e 80, os direitos no trabalho de Michael McCann demonstram como o litígio pode proporcionar experiências de fortalecimento e identidade para os participantes de movimentos sociais, mesmo quando não produz em grande escala mudanças nas políticas públicas. Embora a luta pela eqüidade salarial tenha surgido após a crescente participação das mulheres no mercado de trabalho, dentro dos sindicatos e através do movimento feminista, foi em última instância a vez que os litígios tiveram o impacto mais profundo e duradouro sobre as trabalhadoras (VERONESE: 2015, p. 292). Embora as vitórias antecipadas nos tribunais tenham sido rapidamente substituídas por repetidas derrotas após a ascensão do movimento legal conservador nos anos 80, o legado benéfico da mobilização legal

\footnotetext{
${ }^{9}$ Da mesma maneira, há uma parte da literatura norte-americana acerca dos movimentos sociais que apresenta o campo jurídico como sendo conservador e com pouca utilidade para o avanço das lutas sociais. Veja, por exemplo: ROSENBERG, Gerald. The dynamic and the constrained court, Abortion anw women's rights e Conclusion: the fly-paper court. In: “The Hollow Hope: Can Courts Bring About Social Change?” Chicago: University of Chicago Press, 2008, p. 9-36, 173-265 e 420-429. Rosenberg analisou o impacto das decisões judiciais sobre as mudanças sociais esperadas pelos grupos e movimentos sociais que entraram na arena jurídica para tal. $\mathrm{O}$ autor privilegiou o estudo do papel do direito na produção de resultados tangíveis para demonstrar que a percepção de um Judiciário como arena de lutas sociais e mobilizador de atores políticos possui pouca sustentação empírica. McCann é uma repreensão da análise cética de Gerald Rosenberg sobre a capacidade dos tribunais de provocar mudanças sociais devido à sua impotência para realizar autonomamente revisões de políticas públicas em larga escala e de cima para baixo.

${ }^{10}$ Justiça aqui no sentido de aplicar e manter direitos civis.
} 
foi capturado por sua capacidade de fornecer experiências de politização para as trabalhadoras, para legitimar suas reivindicações através de um discurso de luta por direitos, em forjar oportunidades políticas para a ação coletiva, elevando as expectativas e cultivando uma consciência legal duradoura. A mobilização legal pode raramente ser capaz de promover mudanças de grande escala, de cima para baixo, mas é eficiente em proporcionar um espaço para a reconstituição de relações e identidades sociais. E enquanto a lei pode representar uma fonte de poder privilegiado, ela pode simultaneamente capturar as aspirações dos mais necessitados, tornando-se assim uma fonte legítima de direitos, inclusão e capacitação.

A mudança do ambiente de trabalho no pós-guerra é destacada como uma pré-condição importante para a mobilização social, como a rápida e constante entrada histórica das mulheres no local de trabalho. No entanto, uma vez que faziam parte da força de trabalho, as mulheres descobriram uma discriminação desenfreada e até mesmo uma segregação baseada no gênero. Tais práticas discriminatórias tiveram a consequiência involuntária de forjar a solidariedade entre as trabalhadoras, concentrando um grande número de mulheres, tais como secretárias, operadoras de dados, enfermeiras, vendedoras, assistentes sociais, bibliotecárias, professoras e outras operárias em situações semelhantes de trabalho. "Os empregadores encorajaram uma maior identidade de grupo entre as mulheres" (Op. Cit.: 1994, p. 113).

Uma vez que os laços de solidariedade foram forjados e as queixas comuns compartilhadas, as mulheres se tornaram cada vez mais ativas dentro dos sindicatos. A sindicalização das mulheres era uma pré-condição essencial, bem como um resultado, do movimento de equidade de remuneração. Os sindicatos tornaram-se a principal fonte de dinheiro para a assistência técnica. Os advogados rapidamente se envolveram também na campanha e o movimento de equidade salarial logo começou a se inspirar no legado da reforma legal baseada em direitos dentro da moderna cultura política norte-americana. Esses casos judiciais contribuíram para a passagem de uma percepção das mulheres lutando por oportunidades expandidas para um desafio político efetivo (Ibid: p. 94).

Porém, em meados da década de 1980 o movimento legal conservador começou a permear a jurisprudência americana e os tribunais começaram a rejeitar a porta de acesso a reivindicações de valor comparável baseadas no gênero. Os empregadores invocaram um discurso em defesa do "mercado livre" como confronto aos argumentos de discriminação. 
Apesar dos curtos sucessos nos tribunais, obtidos pelo movimento de equidade de remuneração, McCann argumenta que as estratégias de litígio tinham uma série de efeitos profundos e benéficos. Para o autor, os ativistas não nascem, mas são forjados pela experiência social. A maioria dos ativistas de equidade salarial entrevistados por McCann creditaram as decisões de pequenos casos como sendo geradoras de seu próprio interesse pessoal e de envolvimento na causa.

Com base em litígios anteriores do movimento de direitos civis, os ativistas da eqüidade salarial recorreram a um discurso jurídico mobilizador e capacitador, o "discurso dos direitos" que capacitou as mulheres trabalhadoras, permitindo-lhes identificar e criticar as relações hierárquicas as quais estavam envolvidas. Quando a idéia de valor comparável ou de equidade de remuneração pôde ser enquadrada pelos advogados em termos de direitos contra a discriminação salarial, ela adquiriu muita credibilidade e poder.

Para o autor, o direito não é um instrumento para resolver disputas tanto quanto é um terreno de conflito ou uma arena de luta. A própria idéia de lei estabelecida em si é um paradoxo, já que as normas e direitos legais raramente persistem como incontestáveis, estando sujeitas a batalhas constantes (no contexto estadunidense), sendo sucesctível de aplicação em diferentes contextos relacionais. É própio do Direito a ambigüidade de simultaneamente servir como um recurso para restringir e para permitir a mudança social. Tudo dependerá dos atores que acessam o Judiciário e dos usos que lhe atribuem.

Ao ver a Justiça como recurso que se converte em instrumentos privilegiados na ação coletiva dos movimentos sociais, para Michael McCann é constituída uma bottom up jurisprudence (COMAILLE: 2009, p. 106). Os efeitos destas estratégias em relação ao Direito e a Justiça são tanto "reais e concretos" quanto simbólicos, uma vez que atuam sobre as representações que os cidadãos possuem daquilo ao qual estão submetidos e de suas percepções sobre os papéis do Direito e do Judiciário, até adquirirem uma consciência dos direitos ou dos seus direitos. Para o autor, os processos judiciais podem ser catalisadores de processos políticos ${ }^{11}$.

\footnotetext{
${ }^{11}$ Desse contexto de análise veio muito da esperança de Werneck Vianna em suas posições iniciais acerca das possíveis atuações do Judiciário brasileiro após a reforma democrática de 1988. Sua expectativa era ver um Judiciário como limitador do poder do Estado e arena de lutas políticas e socais.
} 


\section{CONSIDERAÇÕES FINAIS}

A partir dos autores estudados é possível perceber que apesar dos usos e atuações contemporâneas do Judiciário ser resultante de contextos de oposição a um Estado forte e interventor, há diferentes formas de administrar as tensões nos conflitos sociais e políticos por intermédio do Judiciário nos contextos brasileiro e estadunidense.

No primeiro contexto, a atuação política dos juristas se dá por meio da judicialização que não é oriundo de um movimento social, mas que se trata de uma categoria positivada pelo direito brasileiro. A judicialização dispõe do paradoxo de se ter um Estado interventor após um contexto de reforma política anticentralizador.

No segundo contexto, a atuação política dos juristas se dá por meio de ativismo judicial, originário dos movimentos sociais e suas lutas por reconhecimento de direitos. O Judiciário é uma arena de demanda de direitos politicamente engajados, tendo por dilema a luta por direitos sociais dentro de uma lógica de mercado neoliberal. As práticas discriminatórias dos empregadores no contexto norte-maericano estudado tiveram a conseqüência involuntária de forjar a solidariedade entre as trabalhadoras, impulsionando a contrução de um contexto de um Judiciário como arena de lutas por direitos.

Enquanto que no contexto estadunidense a sociedade pode (e consegue) constranger o Estado por meio das leis (formalidade), dos movimentos sociais (reconhecimento de direitos na arena judicial) e do ativismo judicial enquanto ferramenta política de transformação social, no Brasil, o Estado constrange a sociedade, onde a judicialização da política e das relações sociais acabam por servir mais como instrumento reforçador do poder estatal e de sua intervenção na sociedade, mesmo sendo esse movimento derivado de processos não intencionais de reforço de governos unitários e centralizadores (Op. Cit.: 2007, p. 45). Sendo esta uma interpretação dentro de uma dicotomia clássica entre sociedade e Estado, enquanto categorias analíticas. "O boom da litigação é um fenômeno mundial, convertendo a agenda do acesso à Justiça em política pública de primeira grandeza" (Ibid, p. 40), mas com usos e consequências contextuais bem distintas, reforçando que o pensamento jurídico é também construtivo de verdades e realidades sociais e não só reflexo dessas realidades. 


\section{REFERÊNCIAS}

CAPPELlETTI, Mauro; GARTH, Bryant. Acesso à Justiça. Porto Alegre: Sergio Antonio Fabris Editor, 1988.

COMAILLE, Jacques. O Modelo de Janus da regulação jurídica: O carácter revelador das transformações do estatuto político da justiça. Revista Crítica de Ciências Sociais, 87 | 2009, 95-119.

LIMA, Roberto Kant de. Sensibilidades Jurídicas, Saber e Poder: Bases Culturais de Alguns Aspectos do Direito Brasileiro em Uma Perspectiva Comparada. In: Anuário Antropológico, v. 2, p. 25-51, 2010.

MCCANN, M. W. Rights at Work: Pay Equity Reform and the Politics of Legal Mobilization. Chicago: University of Chicago Press, 1994.

O'CONNOR, Karen; EPSTEIN, Lee. The Rise of Conservative Interest Group Litigation. The Journal of Politics, Vol. 45, No. 2, 1983, pp. 479-489.

ROSENBERG, Gerald. The Dynamic and the Constrained Court, Abortion Anw Women's Rights and Conclusion: the Fly-Paper Court. In: "The Hollow Hope: Can Courts Bring About Social Change?" Chicago: University of Chicago Press, 2008, p. 9-36, 173-265 e 420-429.

SILVA, C. A. Promotores de Justiça e Novas Formas de Atuação em Defesa de Interesses Sociais e Coletivos. Revista Brasileira de Ciências Sociais, v. 16, n.45, p. 127-144, fev 2001b.

VERONESE, Alexandre. Judicialização das Telecomunicações no Brasil: Disputas Sobre Direitos dos Consumidores e Regulação. Revista Direito e Práxis, vol. 6, núm. 12, 2015, pp. 283-325.

VIANNA, Luiz Werneck; BURGOS, Marcelo Baumann; SALLES, Paula Martins. Dezessete Anos de Judicialização da Política. Tempo social. 2007, vol.19, n.2, pp.39-85.

WERNECK VIANNA, L.; REZENDE DE CARVALHO, M. A.; CUNHA MELO, M. P.; BAUMANN BURGOS, M. A Judicialização da Política e das Relações Sociais no Brasil. Rio de Janeiro: Revan, 1999.

Data de Submissão: 24/03/2020

Data de Aceite: 16/04/2020 